\title{
Testing Main and Interactive Effect of Personal Coping and Social Support on Work Family conflict
}

\author{
Aneel Kumar* \\ PhD. Scholar, Department of Business Administration, Sukkur Institute of Business \\ Administration, Sukkur-65200, Sindh Pakistan \\ Ghulam Ali Arain \\ Assistant Professor, Department of Business Administration, Sukkur Institute of Business \\ Administration, Sukkur-65200, Sindh Pakistan
}

\begin{abstract}
:
Managing the work family conflict is essential to perform at work and home effectively. The individuals utilize lots of their efforts to ease the work family conflict (WFC). This research investigated the role of personal coping (PC) strategies and the social support (SS) an individual receives in decreasing the level of work family conflict (WFC). Survey method was used to collect the data from Pakistan. The results of this study revealed that PC and SS are negatively associated with WFC and SS was found as moderator in the relationship between PC and WFC. The negative relationship between the PC and WFC was stronger when SS was low as compared to when it was high, whereas the excessive use of resources (i.e., coping and social support) together increased the WFC. This research has contributed by determining the role of SS as moderator in relationship between PC and WFC. Implications of the study are discussed.
\end{abstract}

Keywords: Work Family Conflict (WFC), Personal Coping (PC), and Social Support (SS)

Page: 87 - 101

*Email: aneelkumar.phd@iba-suk.edu.pk 


\section{Introduction}

Practically in the busy schedule of work and family activities, it is really difficult to have fair balance of work and life. There are only a few fortunate people who are enjoying the balance of work and life, while for the rest managing the work family activities is really becoming an uphill task. Sometimes individuals are doing well at work, but their family demands are not allowing them to concentrate on their work activities and sometimes vice versa may happen. The ultimate outcome of this interrole conflict arises in shape of work family conflict (WFC).

This research thought that what could be the sources to reduce the WFC. After having a brief review of the literature we decided to determine the role of personal coping (PC) and social support (SS) in easing the WFC. Many researchers have used these two terms separately as an antecedent of WFC, but the additive and interactive effect of these two on WFC has never been tested. Somech \& Zahavy (2012) tested the PC and organizational support as antecedents WFC and suggested to test the effect of PC with combination of supervisory and co-workers support on WFC. Wadsworth \& Owens (2007) tested the negative association of SS with WFC. Kossek et al. (2011) investigated the negative effect of supervisor support on WFC. Thus this research considered the various sources of support that an employee receives informally within the organization from supervisors and coworkers and the support an employee receives outside the organization from his/her family.

This research hypothesized that the PC level of an individual along with the SS could be very effective in easing the level of WFC among the employees.

\section{Theoretical Framework and Hypotheses}

\subsection{Work family conflict}

Various scholars have given the definitions of work-family conflict (WFC) but the most frequently quoted definition of WFC is given by the Greenhaus \& Beutell (1985). They define WFC as "a form of role conflict in which the role pressures from work and family domains are mutually incompatible in some respect that is participation in the work (family) role is made more difficult by virtue of participation in the family (work) role" ( 1985: 77).

The initial work on WFC is well-documented and summarized by Greenhaus \& Beutell (1985).

Based on literature review of Greenhaus \& Beutell (1985), it becomes apparent that initial concept of WFC can be traced to the work of Kahn et al. (1964) but these researchers did not test their concept empirically. The most frequently quoted definition of WFC proposed by Greenhaus \& Beutell (1985) is also based on the work of Kahn et al. (1964). As the literature review of Greenhaus \& Beutell (1985) suggests, most probably the proper measurement instrument on WFC was initially developed by Werbel (1978). It consisted of four closed ended items. Before the Carlson et al. (2000) scale, the scales of WFC developed by Burke et al. (1980), Kopelman et al. (1983) were used in many empirical studies frequently. Overall on the basis of literature review, Greenhaus \& Beutell (1985) proposed three forms of WFC namely, time based conflict, strain based conflict and behavior based conflict. Gutek et al. (1991) further suggested that each of these three forms of WFC have two directions namely, work interfering with family and family interfering with work. Actually they 
divided the WFC into two dimensions mentioned above but they did not develop a measurement instrument for these separate measures. It was Frone et al. (1992) who developed the separate measures for WIF and FIW. Their measure consists of 2 items each for WIF and FIW. Later on Netemeyer et al. (1996) developed and validated a 10 item scale consisting of 5 items each for WIF and FIW. Stephens \& Sommer (1996) also developed a measurement instrument having items for each of the 3 forms of WIF but they did not develop scale for FIW. Although the directions and forms of WFC were already discussed by many researchers (Greenhaus \& Beutell, 1985; Gutek, et al., 1991; Netemeyer, et al., 1996; Stephens \& Sommer, 1996) prior to Carlson et al. (2000) no one operationalized the all directions and forms of WFC. After the brief review of the literature Carlson et al. (2000) developed and validated a brief measure of WFC measuring both directions: (WIF and FIW) and all three forms: (Time, Strain, and Behavior) of WFC. Today the WFC measures of Carlson et al. (2000) are considered as most validated measures of WFC.

\subsection{Personal coping}

The concept of coping is used by the researchers in relationship with stress and the outcomes similar like stress such as depression, tension etc. In literature the definition of coping given by Lazarus \& Folkman (1984) is most commonly quoted. They define coping as, "the person's constantly changing cognitive and behavioral efforts to manage specific external and/or internal demands that are appraised as taxing or exceeding the person's resources" (1984: 19).

The various researchers have used the concept of coping in different ways. The earlier research used coping as the personality trait or styles, but in contrast to this, in the late 1970's other line of research started usinh coping as a process which changes continuously with the context in which the process of coping occurs Lazarus \& Folkman (1984). They described that the process of coping has two major functions: emotion focused coping and problem focused coping. The research on coping as a process to manage the stressful events provided mixed results. The problem focused coping is effective for FIW but for WIF it is found to be less effective and emotions focused coping is found to be a little or unrelated to WFC (Somech \& Zahavy, 2007). Moreover, the use of coping as a process does not specifically deals with the WFC. Specifically for coping with WFC another line of research used coping as a strategy (Hall, 1972; Somech \& Zahavy, 2007). In context of the WFC, the typology of coping strategies developed by Hall (1972) is considered as the pioneering work. Hall (1972) developed 16 strategies for coping with WFC. These strategies were based on three types of roles namely, structural role redefinition, personal role redefinition, and reactive role Behaviour. Typology of Hall (1972) is found to be more related to FIW, but it has not been able to capture the whole area of WFC (Somech \& Zahavy, 2012). Realizing the need for development of the coping strategies which can cover the entire concept of WFC, Somech \& Zahavy (2007) designed the coping strategies which have a significant effect of the both aspect of WFC. They developed four strategies and each of the strategy consisting of two sub categories representing WIF and FIW. These strategies were super at home and super at work, good enough at home and good enough at work, priorities at home and priorities at work, delegating at home and delegating at work. Somech \& Zahavy (2007) strategies are preferred in this study as compared to the others because these strategies provide separate measurement instruments for both aspect of WFC (WIF and FIW) separately. These strategies have also been validated empirically by Somech \& Zahavy (2007, 2012). 


\subsection{Social support}

The earlier concept on SS can be traced to the work of Cobb (1976). He defines SS as, "information leading the subject to believe that he is cared for and loved, that he is esteemed and valued, that he belongs to a network of communication and mutual obligations." (1976: 300). Cobb (1976) initially discussed the SS as moderator of life stressors.

Usually an individual person receives three types of SS namely, support from organization, support from work sources and support from nonwork sources (Wadsworth \& Owens, 2007). The discussion of organizational support is beyond the scope of this paper, because the effect of PC and organizational support has already been empirically studied by Somech \& Zahavy (2012). So this research has taken into account the effect of PC and work \& nonwork related SS on WFC.

The dependent measure - WFC used in this study has been used by researchers as an antecedent as well as an outcome frequently. Many researcher have used WFC as an antecedent, the existence of which creates positive and negative outcomes such as strain (Kalliath, Hughes, \& Newcombe, 2011), job satisfaction, affective commitment (Liao, 2011), turnover intention (Haar, Roche, \& Taylor, 2012), organizational citizenship behaviour (Beham, 2011). Many other researchers have also used WFC as an outcome frequently. The antecedents of WFC frequently researched are family supportive perception (Lauzun, Major, \& Jones, 2012), gender \& work family demands (Mortazavi, Pedhiwala, Shafiro, \& Hammer, 2009), negative affectivity \& work overload (Karatepe, Kilic, \& Isiksel, 2008) etc. This research was interested in determining the effect of factors which could reduce the level of WFC among employees. So after reviewing the literature, this research focused on the role of PC and SS in reducing WFC.

\subsection{The additive model}

The association of PC and SS with WFC has been tested empirically by many researchers. Wadsworth \& Owens (2007) empirically tested and found the negative association of SS with WIF and FIW. Kossek et al. (2011) conducted meta-analysis of supervisory family support and WFC. They included 85 studied in their meta-analysis and their results revealed the negative association of supervisory family support with WFC. Lauzun et al. (2012) also found negative association of supervisory family support with WFC. Thus many researchers have found negative association of supervisory support with WIF and FIW (Hsu, Chen, Wang, \& Lin, 2010; Karatepe, et al., 2008). Thus this research reviewed the various sources of SS that an individual received within the organization from supervisors, coworkers and outside the organization from his/her family in order to ease WFC. Apart from the SS the researchers have also empirically tested and found that PC level of an individual also plays crucial role in easing the WFC. PC strategies that an individual develops are found to have significant negative association with WFC (

Literature review suggested that researchers have predicted the WFC separately from PC and SS. The additive or combined effect of PC and SS in easing WFC in not tested. This research has taken into account the PC and SS together to see what is the extent to which the PC level of an individual along with the SS together reduces the WFC. Thus on the basis of above discussion the hypotheses for the additive effect of PC and SS is developed as: 
Hypothesis 1(H1): Personal coping and social support are negatively associated with work family conflict (WFC)

\subsection{The interactive model}

Somech \& Zahavy (2012) tested the additive and interactive effect of PC and organizational support on WFC and suggested that the informal support provided by supervisors and coworkers and the support an individual receives outside the organization from other sources such as family, may also be crucial in lessening WFC. As discussed earlier supervisory and coworker support is the work related support, but apart from that an individual also receives non-work related support from his/her family as well which also helps in reducing the WFC. Thus we combine the work and non-work related SS together to develop the SS construct.

Cobb (1976) initially discussed the SS as moderator of life stressors. In WFC relationships SS is used as an antecedant as well as moderator by researchers (Ahmad, 1997; Haar, 2004; Yildirim, 2008). Another initial stimuli to use the SS as moderator was based on Somech \& Zahavy (2012)'s future directions. Moreover, support for interactive model can be derived from conservation of resource theory (Hobfoll, 1989). According to this theory people use resources such as personal characteristics including PC in resisting the stress, whereas SS adds in preserving the valued resources but SS may also lessen or reduce the individual resources. Individuals may utilize more PC skill to reduce the WFC as the level of SS reduces. Similarly SS received by the individuals reduces their need of investing in unnecessary PC resources (Lapierre \& Allen, 2006). For interactive effect of coping and organizational support Somech \& Zahavy (2012) argued that it would be ineffective to utilize both simultaneously. Utilization of both together might cause resource loss instead of gain. Thus it is hypothesized that people will utilize more PC when they are receiving low level of SS and if people are utilizing more PC resources and also having sufficient SS then instead of reduction in WFC, the excessive use of both might increase the WFC.

Hypothesis 2 (H2): The social support (SS) moderates the relationship between personal coping (PC) and work family conflict (WFC) such that the negative relationship between personal coping (PC) and work family conflict (WFC) will be stronger when social support (SS) is low as compared to when social support (SS) is high.

\section{Method}

\subsection{Data and Sample}

This banking sector of Pakistan was selected as sample for this study. The primary data was collected from the employees of the banking sector of Pakistan through a Likert type of survey questionnaire. The researcher himself visited the various banks and by hand distributed the questionnaires among the employees of each bank. The researcher also assisted the respondents in filling the questionnaires properly. The rationale to select the banking sector employee was that there is huge completion in the banking sector now a days. Banks are forced to cut off the salaries of employee due to the recession, but the workload is increasing conversely on the employees. In this situation, it was possible that the employees may experience WFC and if so what are the resources they are utilizing to cope with the WFC. 
Out of 350 distributed questionnaires, 243 properly filled questionnaires were selected for this study. The response rate was around $69 \%$. In the preliminary screening 16 respondents were identified as outlier and were excluded from further analysis. Thus the sample of 227 was kept for final analysis. This total sample comprised $79 \%$ males and 21 percent females. The ages of the $57 \%$ respondents were between 20 to 29 years, $28 \%$ were between age group of 30 to 39 years, $11 \%$ were between 40 to 49 years, and 04 percent were of the age above 50 years. The education of the $85 \%$ respondents was 16 years and above, 14 percent had 14 years education while only $01 \%$ had 12 years education. With respect to experience of the respondents, $40 \%$ sample had experience of 01 to 02 years, $27 \%$ had experience of 2 to 5 years, and $19 \%$ had experience of 5 to 10 years while $14 \%$ had experience of above 10 years.

\section{Measures}

All the measures were measure, through the five point likert scale questionnaires adapted for this study. Work family conflict was measured by 18 items scale adapted from Carlson et al. (2000). Personal coping is measured through a 22 item scale adapted from Somech \& Zahavy (2007). Social supports (i.e., Supervisory and Co-workers) is measured by a 10 item scale adapted from Allen (1998) while family Support was measured by 03 items scale adapted from Allen et al. (1998).

\subsection{Control variables}

On the basis of previous empirical studies the demographic variables such as Gender, Age,

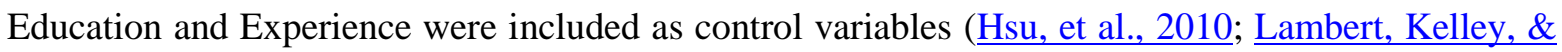
Hogan, 2012; Liao, 2011).

\subsection{Data Analysis}

The process of data analysis and hypothesis testing was conducted through the statistical package for social sciences (SPSS) and analysis of the moment (AMOS). Firstly preliminary data screening tests such as missing values, outliers, normality, descriptive statistics, and correlational analyses were performed. The structural regression (SR) models were tested through AMOS. Moderation hypothesis was tested through the Orthogonalizing technique developed for latent variables used in structural equation modeling by Little et al. (2006). According to this technique orthogonalized indicators are created by forming each possible product term for the two sets of indicators for two latent constructs. Each of the resulting product terms are individually regressed on all indicators of the two latent constructs. If we have forty product terms as in our case then each of these forty product terms will be regressed on all indicators of latent construct one by one and in this way 40 standardized residuals will be saved. These resulting forty standardized residuals are called the orthogonalized product terms. Accordingly the correlations between the residual variances of the interaction indicators are specified. The results of descriptive statistics and correlation are given in table 1 . 


\section{TABLE 1}

Descriptive Statistics: Mean, Standard Deviation and Inter-Item Correlations

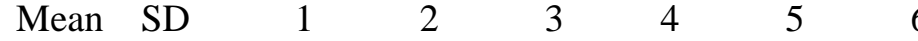

$\begin{array}{lccccccccc}\text { 1. Gender } & \mathrm{NA}^{\mathrm{a}} & ---- & & & & & & \\ \text { 2. Age } & 1.62 & .83 & -.19^{* *} & & & & & \\ \text { 3. Education } & 1.16 & .39 & -.01 & -.07 & & & & \\ \text { 4. Experience } & 2.07 & 1.07 & -.14^{*} & .77^{* *} & 06-. & & & \\ \text { 5. PC } & 3.33 & .96 & .08 & .01 & .01 & -.06 & .93 & \\ \text { 6. SS } & 3.28 & .76 & .07 & .11 & -.07 & .02 & .46^{* *} & \mathbf{. 8 2} \\ \text { 7. } \mathrm{WFC}^{\mathrm{b}} & 3.02 & .91 & -.09 & -.06 & -.03 & -.03 & -.43^{* * *}-.51^{* * *} \\ * \mathrm{p}<0.05, * * \mathrm{p}<0.01, * * * \mathrm{p}<.001 & & & & & & \end{array}$

a. $\quad$ NA = Not Applicable, WFC=Work Family Conflict, $\mathrm{PC}=$ Personal Coping, $\mathrm{SS}=$ Social Support

Note. Diagonally in bold are given the composite reliabilities; $\mathrm{N}=227$

We performed the confirmatory factor analysis (CFA) to check the model fit in the context used in this study. The fit indices included were CMIN/df, Tucker-Lewis Index (TLI), Comparative Fit Index (CFI), and Root-Mean Square Error of Approximation (RMSEA) (Hair, Black, Babin, \& Anderson, 2010). When CFA was performed for the first time to check the model fit, the model fit indices were relatively poor $(\mathrm{CMIN} / \mathrm{df}=2.99, \mathrm{CFI}=.708$; $\mathrm{TLI}=.696$, $\mathrm{RMSEA}=.094)$. In order to improve model fit, all the items with low factor loadings were removed. A total of 34 items was removed. Out of these 34 items, 12 items were removed from WFC measure, 08 items were removed from the measure of SS and 14 items were removed from the measure of PC, then the model fit indices improved significantly to acceptable levels $(\mathrm{CMIN} / \mathrm{DF}=2.36, \mathrm{CFI}=.92, \quad \mathrm{TLI}=.905$, RMSEA = .078).

To assess the proposed model, two alternative measurement models were also analyzed (Bentler \& Bonnet, 1980). The first alternative model in which all the items were loaded on a single factor, showed poor fit to data $(C M I N / d f=7.10, \mathrm{CFI}=0.62$; TLI $=0.57, \mathrm{RMSEA}=0.16)$. The second model (in which a four factor solution was tested by dividing the work family conflict into two factors namely: work interference with family and family interference with work) exhibited a near fit to the data $(C M I N / d f=2.64, \mathrm{CFI}=0.90 ; \mathrm{TLI}=0.88$, RMSEA $=0.08)$. Moreover the correlation between the work interference with family and family interference with work was also higher $(\mathrm{r}=$ .85) which was exploiting the validity of the measures. Kline (2011) recommended that in order to establish discriminant validity the correlations among the indicators of same factor should be greater than cross factor correlations but in our case the correlations between the indicators of the two 
factors of WFC were mostly similar. Overall Comparison of the three-factor model with alternative models showed a superior fit for three-factor model.

The procedure recommended by Hair et al. (2010) was adopted to check the composite (overall internal consistency) reliability and the discriminant \& convergent validity of the measurement scales.

A common latent factor test was conducted to check the issue of common method variance (Podsakoff, MacKenzie, Lee, \& Podsakoff, 2003). The results did not show any shared variance among the items.

\section{Results}

To test, first main (Additive) effect model as well as interactive effect model, we developed structural regression (SR) models using AMOS. In the first model we hypothesized that PC and SS are negatively associated with WFC. The results of first SR model depicted a good fit to the data. These fit indices for this model are given in table 2.

TABLE 2

Structural Model 1 Results

Model Description CMIN/df TLI CFI RMSEA

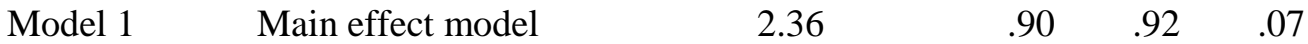

Note: Tucker-Lewis Index (TLI), Comparative Fit Index (CFI), and Root-Mean Square Error of Approximation (RMSEA)

Furthermore, we also added 4 covariates (Gender, age, education, experience) to above model which resulted in poor fit of the $\mathrm{SR}$ model $(\mathrm{CMIN} / \mathrm{df}=2.86, \mathrm{CFI}=.84, \mathrm{TLI}=.82, \mathrm{RMSEA}=.09)$ and the effect of controls on the WFC was also insignificant. So controls were removed from further analysis.

In the second (Interactive effect) model we hypothesized SS as moderator in the relationship between PC and WFC. Our interactive model showed closer fit indices. The fit indices for this model are given in table 3 . 
Aneel et al. / Effect of Coping and Social Support on Work Family Conflict

TABLE 3

Structural Model 2 Results

Model Description CMIN/df TLI CFI RMSEA

$\begin{array}{llllll}\text { Model } 2 & \text { Interactive effect model } & 1.46 & .92 & .93 & .04\end{array}$

Note: Tucker-Lewis Index (TLI), Comparative Fit Index (CFI), and Root-Mean Square Error of Approximation (RMSEA)

The SR model 1 results for additive effect of PC and SS showed negative association of PC ( $\beta=$ $.255, \mathrm{p}<.01)$ and $\mathrm{SS}(\beta=-.413, \mathrm{p}<.01)$ with WFC which supported our main effect hypothesis of negative relationship of PC and SS with WFC.

The SR model 2 results for interactive effect of PC and SS $(\beta=.419, \mathrm{p}<.01)$ showed that SS moderates the relationship between PC and WFC significantly.

The results for main effect as well as for interactive effect are given in table 4 .

TABLE 4

Results of Structural Regression Models for Checking the Additive and Interactive Effects of

Personal Coping and Social Support on Work Family Conflict

\begin{tabular}{|c|c|c|c|}
\hline & \multicolumn{3}{|c|}{ Work Family Conflict (WFC) } \\
\hline & Unstandardized $\beta$ & $\underline{S E}$ & $p$ - value \\
\hline \multicolumn{4}{|l|}{ Additive Model: } \\
\hline Personal Coping (PC) & $-.255^{* * *}$ & .082 & .000 \\
\hline Social Support (SS) & $-.413^{* * * *}$ & .092 & .000 \\
\hline \multicolumn{4}{|l|}{ Interactive Model: } \\
\hline PC X SS & $.419^{* * * *}$ & .099 & .000 \\
\hline
\end{tabular}

$* \mathrm{p}<0.05, * * \mathrm{p}<0.01, * * * \mathrm{p}<.001, \mathrm{~N}=227$

After confirmation of moderation we plotted the slopes to check the effect of moderator on the relationship between PC and WFC. 
The slopes for the relationship between PC and WFC moderated by SS showed that when there was a low level of SS, the increase in personal coping was decreasing the WFC whereas when the level of SS was high, the increase in personal coping was also increasing the WFC rather than decreasing it, which is consistent with our hypothesis 2 . The Slope of interactive effect of PC and SS on WFC is given in figure 1.

FIGURE 1

Slope of Interactive Effect of Personal Coping and Social Support on Work Family Conflict

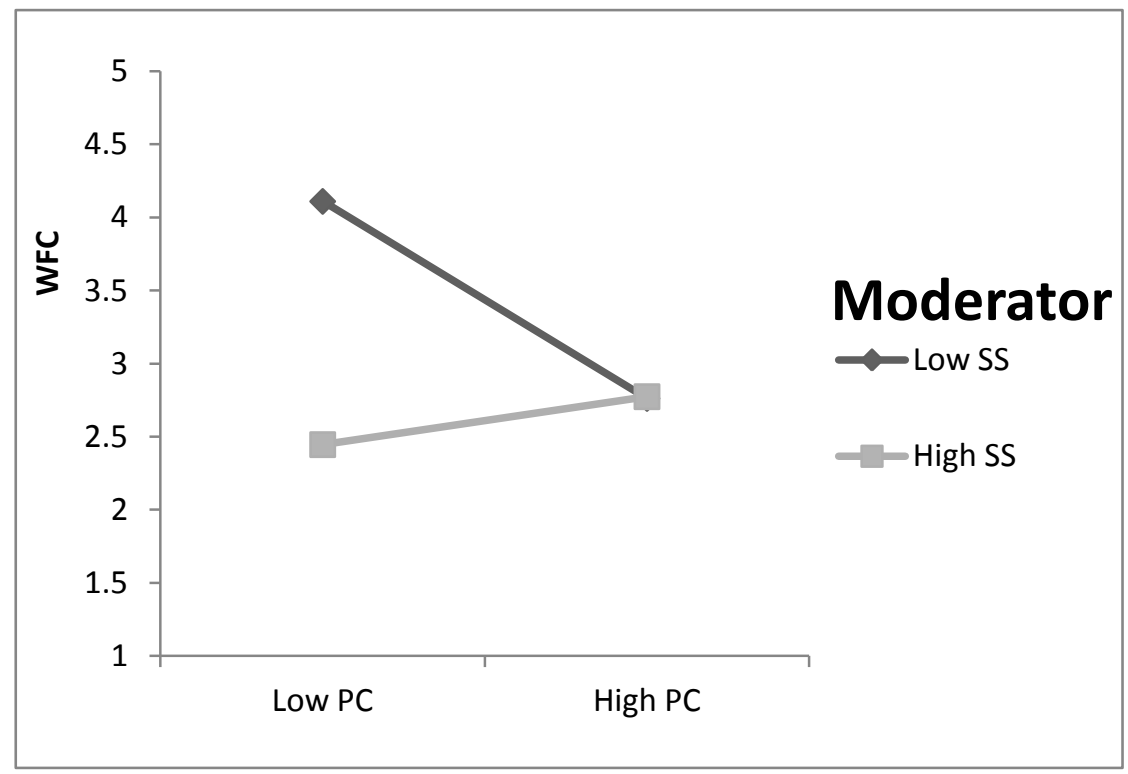

\section{Discussion}

The purpose of this research was to determine the extent to which the PC and SS can be helpful in reducing the WFC and whether the low or high level of SS makes the effect of PC on WFC stronger or weaker.

In the results two models were discussed. The results of both models are discussed separately.

\subsection{The additive model}

In hypothesis-01we hypothesized that PC and SS have negative associations with WFC. The results of the additive model are in line with our hypothesis. Discussing the role of PC and SS in reducing the WFC, it was found that both are very helpful in reducing the WFC, but $\mathrm{SS}(\beta=-.413, \mathrm{p}<.01)$ is found to be more important in reducing the WFC as compared to PC $(\beta=-.255, \mathrm{p}<.01)$. The blend of SS is adding to ease more WFC. Supervisors support \& coworkers support in the time of distress inside the organization and family's support in work activities are really making it easier for an employee to experience less WFC. These results are also consistent with Lapierre \& Allen (2006), Somech \& Zahavy (2012). Thus over all PC and SS together are found as strong predictors of WFC. Over all the additive effect of both is truly important to overcome the WFC. 


\subsection{The interactive model}

For the interactive model we hypothesized that SS moderates the relationship between PC and WFC such that the negative relationship between PC and WFC will be stronger when SS is low as compared to when SS is high. Our significant moderation results of SR model 2 suggested that SS is found as moderator in the relationship between PC and WFC.

Moreover the direction of the moderation can be confirmed from the slopes of figure 1 . We can derive the result very easily that as the level of PC was increasing the level of WFC was decreasing significantly when SS was at low level as we hypothesized. Moreover the high level of SS changed the direction of relationship between PC and WFC. When SS was high, the increase in PC was also increasing the WFC instead of decreasing it. This is very much consistent with the view that PC effort of the individual and SS together may result in loss of resources instead of gain (Somech \& Zahavy, 2012). As people receive low level of support from others then they heavily rely on themselves and develop the coping strategies to ease the WFC but when PC as well as SS both are increasing then these are resulting in increase in WFC.

Conclusively, the results of this study suggest that PC as well as SS can be crucial in decreasing the level of WFC. SS was found as moderator in the relationship between PC and WFC. The PC and SS interacts such that increase in PC and the decrease in SS reduces the WFC while utilization of both resources at the same time by the employees result in waste of resources which in turn leads toward increase in WFC rather than decreasing it.

\section{Theoretical and Practical Implications}

The organizations to provide the employees an environment in which employees are able to interact with their supervisors and coworkers to gain the sufficient amount of SS form them continuously. Organizations are required to develop not only coping skills of their employees but they need to provide them the environment in which employees can delegate their work responsibilities to each other and they are good enough to support each other. The supportive supervisor can also be very helpful for employees to manage their WFC. Some care must be taken for managing the level of SS and Coping simultaneously. If individuals are making investments in their coping skills and at the same time if they are receiving high SS then it is creating the WFC rather than decreasing it because an individual's investment in resources to enhance PC skills and high SS received is actually resulting in exploitation of resources. So organizations must make sure that employees really needed to enhance their PC skills or SS is good enough to ease the WFC. Thus over all the utilization of PC and SS can be very fruitfull for an organization to ease the WFC.

\subsection{Limitations}

The use of cross sectional data may include some common method variance. Most specifically the current policy of two holidays in a week in banking sector in our country may have changed the state of WFC among the employees of banking sector. The issue of WFC may vary from job to job. 


\subsection{Future Directions}

The role of culture can be incorporated to understand the extent to which employees in context of Pakistan utilizes either coping resource or social support. Current policy of two holidays in a week in banking sector might have a significant role in reduction of WFC in the employee. In future this should be accounted for in research. In order to avoid common method variance and establish casual effect, the longitudinal data may be collected. 


\section{References}

Ahmad, A. (1997). Work-Family Conflict and Social Support: A Study of Female Secretaries in Malaysia. Pertanika J. Soc. Sci. \& Hum. 5(2): 93-101, 5(2), 93-101

Allen, M. W., Amason, P., \& Holmes, S. (1998). Social Support, Hispanic Emotional Acculturative Stress and Gender. Communication Studies, 49(2), 139-157.

Beham, B. (2011). Work-family conflict and organizational citizenship behavior: empirical evidence from Spanish employees. Community, Work \& Family, 14(1), 63-80.

Burke, R. J., Weir, T., \& DuWors, J. R. E. (1980). Perceived type a behavior of husbands and wives' satisfaction and well-being. Journal of Occupational Behavior, 1, 139-150.

Carlson, D. S., Kacmar, K. M., \& Williams, L. J. (2000). Construction and initial validation of a multi-dimensional measure of work family conflict. Journal of Vocational Behaviour, 56, 249-276.

Cobb, S. (1976). Presidential Address-1976. Social support as a moderator of life stress. Psychosomatic medicine, 38(5), 300-314.

Frone, M. R., Russell, M., \& Cooper, M. L. (1992). Antecedents and outcomes of work-family conflict: testing a model of the work-family interface. Journal of Applied Psychology, 77(1), 65.

Greenhaus, J. H., \& Beutell, N. J. (1985). Sources of conflict between work and family roles. Academy of Management Review, 10(1), 76-88.

Gutek, B., Searle, S., \& Klepa, L. (1991). Rational versus gender role-explanations for work-family conflict. Journal of Applied Psychology, 76, 560-568.

Haar, J. M. (2004). Work Family conflict and Turnover Intentions: Exploring the moderating effects of work family support. Newzealand Journal of Psychology, 33(1), 35-39.

Haar, J. M., Roche, M., \& Taylor, D. (2012). Work family conflict and turnover intentions of indigenous employees: the importance of the whanau/family for Maori. The International Journal of Human Resource Management, 23, 2546-2560.

Hair, J. F., Black, W. C., Babin, B. J., \& Anderson, R. E. (2010). Multivariate data analysis (7 ed.). Upper Saddle River, NJ: Prentice Hall.

Hall, D. T. (1972). A model of coping with role conflict: The role behavior of college educated women. Administrative Science Quarterly, 17, 471-489.

Hobfoll, S. E. (1989). Conservation of Resources: A New Attempt at Conceptualizing Stress. American Psychologist, 44(3), 513-524. 
Aneel et al. / Effect of Coping and Social Support on Work Family Conflict

Hsu, B. F., Chen, W. Y., Wang, M. L., \& Lin, Y. Y. (2010). Explaining supervisory support to workfamily conflict: The perspectives of guanxi, LMX, and emotional intelligence. Journal of Technology Management in China, 5(1), 40-45.

Kahn, R. L., Wolfe, D. M., Quinn, R., Snoek, J. D., \& Rosenthal, R. A. (1964). Organizational stress. New York: Wiley.

Kalliath, P., Hughes, M., \& Newcombe, P. (2011). When work and family are in conflict: Impact of psychological strain experienced by social workers in Australia. Australian Social Work, 1-17.

Karatepe, O. M., Kilic, H., \& Isiksel, B. (2008). An Examination of the Selected Antecedents and Outcomes of Work-Family Conflict and Family-Work Conflict in Frontline Service Jobs. Services Marketing Quarterly, 29, 1-24.

Kline, R. B. (2011). Principles and practice of structural equation modeling: Guilford press.

Kopelman, R. E., Greenhaus, J. H., \& Connolly, T. F. (1983). A model of work, family, and interrole conflict: A construct validation study. Organizational Behavior and Human Performance, 32, 198215.

kossek, E. E., Pichler, S., Bodner, T., \& Hammer, L. B. (2011). Workplace social support and work family conflict: A meta-analysis clarifying the influence of general and work family specific supervisor and organizational support. Personnel psychology, 64(2), 289-313.

Lambert, E. G., Kelley, T., \& Hogan, N. L. (2012). Work-family conflict and organizational citizenship behaviors. Journal of Crime and Justice, 1-120.

Lapierre, L. M., \& Allen, T. D. (2006). Work-supportive family, family-supportive supervision, use of organizational benefits, and problem-focused coping: implications for work-family conflict and employee well-being. Journal of Occupational Health Psychology, 11(2), 169.

Lauzun, H. M., Major, D. A., \& Jones, M. P. (2012). Employing a Conservation of Resources Framework to Examine the Interactive Effects of Work Domain Support and Economic Impact on Work-Family Conflict. The Psychologist-Manager Journal, 15(1), 25-36.

Lazarus, R. S., \& Folkman, S. (1984). Stress, appraisal, and coping: Springer Publishing Company.

Liao, P. Y. (2011). Linking work-family conflict to job attitudes: the mediating role of social exchange relationships. The International Journal of Human Resource Management, 22(14), 29652980.

Little, T. D., Bovaird, J. A., \& Widaman, K. F. (2006). On the merits of orthogonalizing powered and product terms: Implications for modeling interactions among latent variables. Structural Equation Modeling, 13(4), 497-519.

Mortazavi, S., Pedhiwala, N., Shafiro, M., \& Hammer, L. (2009). Work-family conflict related to culture and gender. Community, Work \& Family, 12(2), 251-273. 
Aneel et al. / Effect of Coping and Social Support on Work Family Conflict

Netemeyer, R. G., Boles, J. S., \& McMurrian, R. (1996). Development and validation of workfamily conflict and family-work conflict scales. Journal of Applied Psychology, 81, 400-410.

Podsakoff, P. M., MacKenzie, S. B., Lee, J.-Y., \& Podsakoff, N. P. (2003). Common method biases in behavioral research: A critical review of the literature and recommended remedies. Journal of Applied Psychology, 88(5), 879-903. doi: 10.1037/0021-9010.88.5.879

Somech, A., \& Zahavy, A. D. (2007). Strategies for coping with work-family conflict: The distinctive relationships of gender-role ideology. Journal of Occupational Health Psychology, 12, 119.

Somech, A., \& Zahavy, A. D. (2012). Coping with work-family conflict: The reciprocal and additive contributions of personal coping and organizational family-friendly support. Work \& Stress,, 26(1), 68-90.

Stephens, G. K., \& Sommer, S. M. (1996). The measurement of work to family conflict. Educational and Psychological Measurement, 56(3), 475-486.

Wadsworth, L. L., \& Owens, B. P. (2007). The effects of social support on work-family enhancement and work-family conflict in the public sector. Public Administration Review, 67(1), 7587.

Werbel, J. D. (1978). Work and physical health. In A. K. Korman (Chair), Management Alienation. Symposium conducted at the annual meeting of the Eastern Academy of Management. New York.

Yildirim, D. (2008). Nurses' work demands and work-family conflict: A questionnaire survey. International

Journal

of

Nursing

Studies,

45:1366-1378 